Natural Hazards and Earth System Sciences, 5, 979-992, 2005

SRef-ID: 1684-9981/nhess/2005-5-979

European Geosciences Union

(C) 2005 Author(s). This work is licensed

under a Creative Commons License.

\title{
Landslide susceptibility assessment of SE Bartin (West Black Sea region, Turkey) by artificial neural networks
}

\author{
M. Ercanoglu \\ Hacettepe University, Engineering Faculty, Department of Geological Engineering, Applied Geology Division, 06532 \\ Beytepe/Ankara, Turkey
}

Received: 8 July 2005 - Revised: 22 November 2005 - Accepted: 22 November 2005 - Published: 5 December 2005

\begin{abstract}
Landslides are significant natural hazards in Turkey, second only to earthquakes with respect to economic losses and casualties. The West Black Sea region of Turkey is known as one of the most landslide-prone regions in the country. The work presented in this paper is aimed at evaluating landslide susceptibility in a selected area in the West Black Sea region using Artificial Neural Network (ANN) method. A total of 317 landslides were identified and mapped in the area by extensive field work and by use of air photo interpretations to build a landslide inventory map. A landslide database was then derived automatically from the landslide inventory map. To evaluate landslide susceptibility, six input parameters (slope angle, slope aspect, topographical elevation, topographical shape, wetness index, and vegetation index) were used. To obtain maps of these parameters, Digital Elevation Model (DEM) and ASTER satellite imagery of the study area were used. At the first stage, all data were normalized in $[0,1]$ interval, and parameter effects on landslide occurrence were expressed using Statistical Index values (Wi). Then, landslide susceptibility analyses were performed using an ANN. Finally, performance of the resulting map and the applied methodology is discussed relative to performance indicators, such as predicted areal extent of landslides and the strength of relation $\left(r_{i j}\right)$ value. Much of the areal extents of the landslides $(87.2 \%)$ were classified as susceptible to landsliding, and $r_{i j}$ value of 0.85 showed a high degree of similarity. In addition to these, at the final stage, an independent validation strategy was followed by dividing the landslide data set into two parts and $82.5 \%$ of the validation data set was found to be correctly classified as landslide susceptible areas. According to these results, it is concluded that the map produced by the ANN is reliable and methodology applied in the study produced high performance, and satisfactory results.
\end{abstract}

Correspondence to: M. Ercanoglu

(murate@ hacettepe.edu.tr)

\section{Introduction}

There has been an increasing interest in natural hazard assessments within the scientific community particularly in the last two decades. Declaration of the decade of 1990-2000 as the International Decade for Natural Disaster Reduction (IDNDR) by the United Nations can be considered as one of the most important milestones in disaster mitigation. The result was encouragement of and support by scientists, society, and governments on focusing on this goal. There is also increasing international interest in landslide assessments and techniques, and a heightened awareness of the socio-economic significance of landslides, which is further enhanced by increased pressures of urbanization and development on the environment (Aleotti and Chowdhury, 1999). Indeed, landslides are one of the most destructive natural hazards in the world, and casualties and property damage caused by landslides are high (Schuster, 1996).

Preparation of landslide inventory and susceptibility maps is one of the most important stages in landslide hazard mitigation. These maps provide important information to support decisions for urban development and land use planning. Also, effective utilization of these maps can considerably reduce damage potential and other cost effects of landslides. However, landslides and their consequences are still a great problem for many countries, particularly those in the developing world. These countries, with rapidly increasing populations, are facing the problem arising from increasing demand for urban lands, at the same time as their limited financial resources hinder mitigation efforts, which should be performed before landslide events occur.

To date, a number of different methods have been developed to predict landslide hazards. They can be divided into two groups as qualitative methods and quantitative methods. These vary from experience-based analyses to complex mathematical, logical, and/or computer-based systems to analyze landslide susceptibility, hazard, and risk. Geomorphologic analyses and direct field mapping methods are considered qualitative methods because they don't yield numeric 


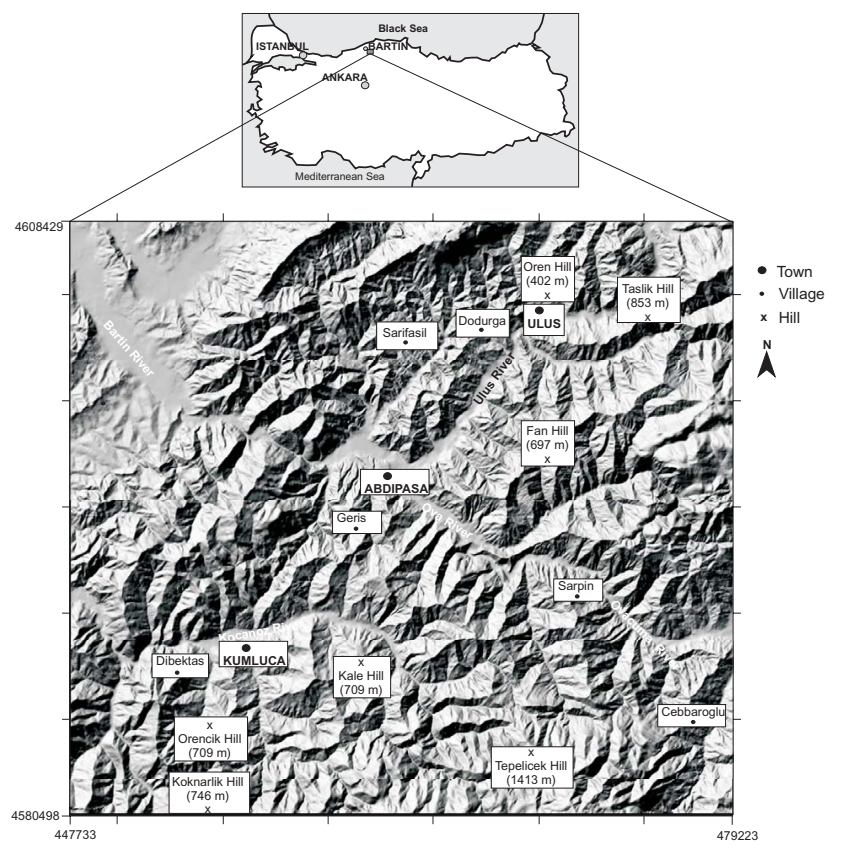

Fig. 1. Location map of the study area.

output with reference to landslide assessment. On the other hand, quantitative methods such as deterministic analyses, probabilistic approaches, statistical methods, and artificial intelligence techniques closely rely on mathematical models and produce numeric outputs. However, no general agreement has yet been reached about the best method for producing landslide hazard assessment maps (Guzzetti et al., 2000). Although all known methods have their advantages and disadvantages, utilization of quantitative methods has become preferred and more commonly used in recent years (Binaghi et al., 1998; Aleotti and Chowdhury, 1999; Guzzetti et al., 2000; Carrara et al., 2003; Ercanoglu, 2003; Ercanoglu and Gokceoglu, 2004; Ercanoglu et al., 2004). In addition, utility of GIS (Geographical Information Systems) has been emphasized in nearly every landslide study published in recent years. Therefore, it can be concluded that the general trend related to landslide assessments is the utilization of quantitative methods and specifically, GIS based ones.

The work presented here is aimed at evaluating landslide inventory and susceptibility in a selected landslide-prone area in the West Black Sea region of Turkey. To achieve this, first a detailed landslide inventory map was prepared by extensive field assessment and air photo interpretations. Secondly, input parameter maps were produced and analyzed together with the landslide inventory map. Since the complex nature of the landslide mechanism and its ability to reflect nonlinearities and complexity, Artificial Neural Network (ANN) was chosen to assess landslide susceptibility, and was then used to evaluate areas susceptible to landslides using a GIS based system. Lastly, performance of the resulting susceptibility map was evaluated and discussed.
In recent years, with an increasing interest, several papers have been published concerning with ANN applications and landslide assessment in the literature (e.g. Lee et al., 2001, 2003; Ermini et al., 2005; Gomez and Kavzoglu, 2005; Yesilnacar and Topal, 2005). With this study, it is expected to satisfy the lack of landslide inventory in some part of West Black Sea region, at least for the study area, and to predict susceptible areas to landslides with an automated landslide database and frequency based ANN model.

\section{General characteristics of the study area}

The West Black Sea region of Turkey is severely affected by landslides and is known as one of the most landslide-prone areas of Turkey. The landslides in this region have frequently been reported in some recent studies (e.g. Temiz, 2000; Ercanoglu and Gokceoglu, 2002; Ercanoglu, 2003; Ercanoglu and Gokceoglu, 2004; Ercanoglu et al., 2004; Duman et al., 2005). In the West Black Sea region, a selected area (Fig. 1) covering $879 \mathrm{~km}^{2}$ and circumscribing six $1 / 25000$ scale topographic maps is considered at the first stage of the study. This area is located approximately $35 \mathrm{~km} \mathrm{SE}$ of Bartin city (see Fig. 1). In order to determine landslide characteristics and locations, extensive field work was done to assess the effects of the bedrock and surficial geology of the study area (Fig. 2). Concurrently, 1/15000 scale aerial photos were interpretated, and identified landslides were checked and mapped in the field. No landslides were identified in lithologic units other than the Upper Cretaceous age Ulus formation. Therefore, the area covered by the Ulus formation is the focus of subsequent analyses and discussion. In other words, due to no landslide records and/or observations in the other lithologic units, they were not taken into consideration for landslide susceptibility analyses.

The Ulus formation covers approximately $572 \mathrm{~km}^{2}(65 \%$ of the original larger study area shown in Fig. 2) comprising the bulk of the hilly topography in the area. The Ulus formation is comprised mostly of sandstones, claystones, and siltstones. At higher elevations, limestones and quartzites are exposed. The Ulus formation represents a typical flysch sequence which is highly susceptible to weathering (Deveciler, 1986; Demir and Ercan, 1999). Although the term flysch refers to "rock material", the landslides in the study area occur within the weathering zone of flysch layers. In other words, landslides in the region occur in the zone of soil type material. The soils contain different particle sizes ranging from pre-dominantly fine grained clayey loams to coarse grained gravel with clasts block size. Based upon field observations, thickness of soil horizons, where the landslides may occur, varies between $0.05 \mathrm{~m}$ to $40 \mathrm{~m}$, and landslides in the study area generally occur within the upper $3 \mathrm{~m}$ to $25 \mathrm{~m}$, and approximately $7.5 \mathrm{~m}$ in average. The other morphometric landslide size parameters, width and length, were also taken into consideration during the field studies. Approximately, the width of the landslides vary from $4.5 \mathrm{~m}$ to several hundred meters, while the length of them vary from $5 \mathrm{~m}$ to 

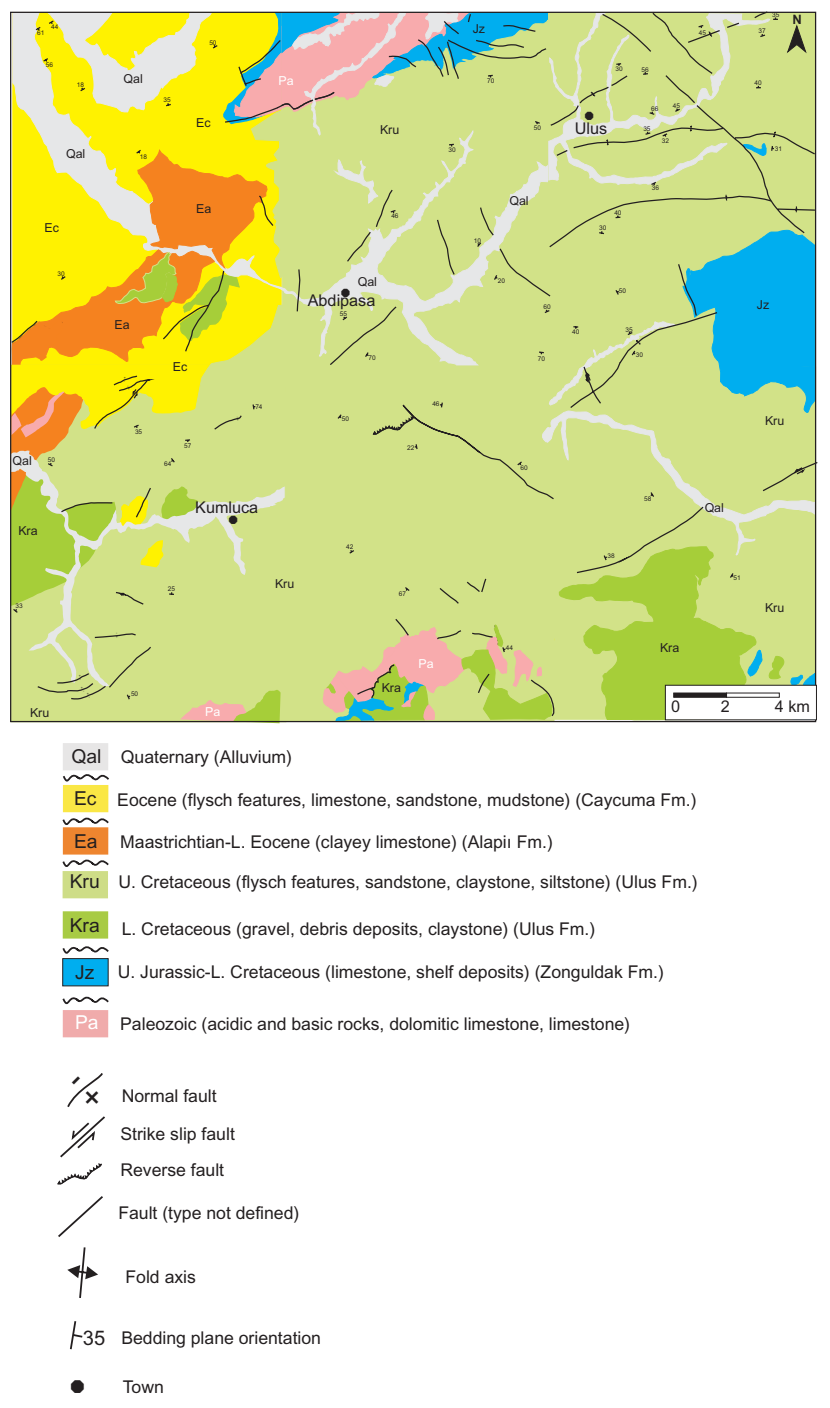

Fig. 2. Generalized geological map of the study area (simplified from Timur et al., 1997).

approximately $700 \mathrm{~m}$. There were no reliable data representing the ages of landslides, most of which were recorded as actual. However, based on the information gathered from the local people, the old ones, just located in the north of Kumluca (see Fig. 1), were reported to have occurred in 1956 after a rainy period in the region.

The main streams in the study area are Bartin, Kocanoz, Ulus, Ova, and Ovacuma Rivers (see Fig. 1). These rivers and their tributaries constitute a dentritic drainage pattern. Elevations in the area range between $44-1413 \mathrm{~m}$, and the highest point in the study area is Tepelicek Hill. There are also other important topographical features such as Taslik, Orencik, Koknarlik Hills (see Fig. 1). Higher elevations are considerably steep (higher than $45^{\circ}$ ) and formed by the resistant bedrock portions of the Ulus formation while at lower elevations more gentle slopes prevail $\left(0^{\circ}-20^{\circ}\right)$. Slope angles range between $0^{\circ}-58^{\circ}$ with an average of $21^{\circ}$. Slope aspects in the study area trend generally in a northwesterly direc-

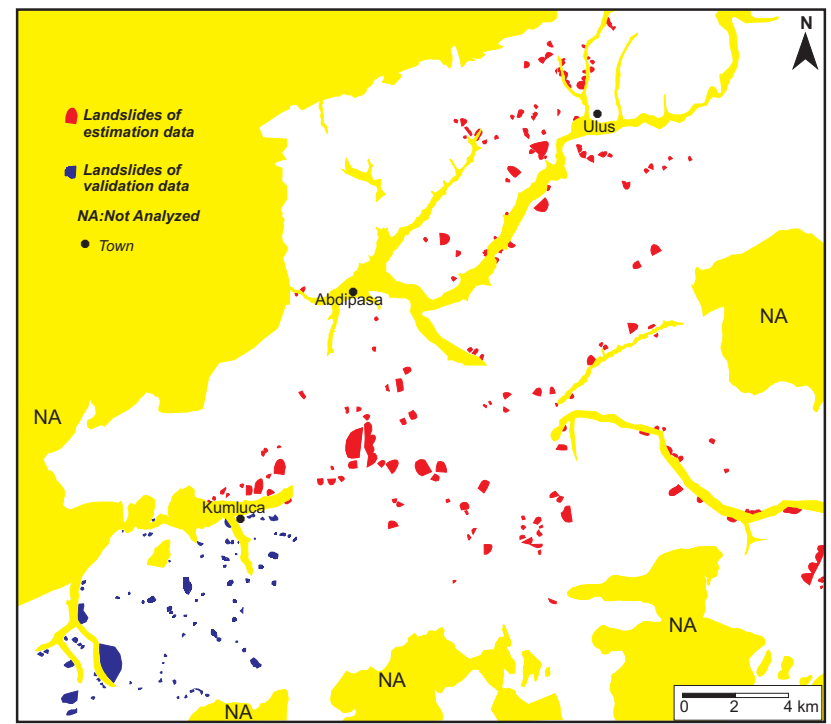

Fig. 3. Landslide inventory map of the study area.

tion. Extensive and thick forests cover the higher and steeper elevations, while farmlands and rangelands are dominant at lower and more gentle slopes. Ulus, Abdipasa, and Kumluca are the main towns and there are also many scattered small villages throughout the study area (see Fig. 1).

\section{Preparation of landslide inventory and parameter maps}

As the first stage of landslide assessment, determining the characteristics of the areas exposed to landslides can provide useful information for identifying future landslide occurrences. For landslide susceptibility assessment, several spatial data layers, or landslide conditioning parameters, are necessary for evaluation, together with the landslide inventory. GIS techniques provide a powerful tool for processing and integrating large amounts of spatial data when combining or performing analyses on these layers. Therefore, whatever methodology is adopted for evaluating landslide susceptibility, utilization of GIS techniques seems inevitable, especially for medium or regional scale studies.

To prepare a detailed and reliable landslide inventory map and database, extensive field work, visual observations, and air photo interpretations were carried out in the study area. In addition to these works, the locations of landslides were also checked by using a GPS (Global Positioning System) receiver with an accuracy of $\pm 5 \mathrm{~m}$ (at $95 \%$ confidence interval). Because landslide characteristics were obtained using an automated method to be discussed in the following paragraphs, field observations were focused on mapping landslide locations as accurately as possible using the combination of these works.

A total of 317 landslides, covering approximately $11 \mathrm{~km}^{2}$ in the study area, were identified and mapped as a result of this effort (Fig. 3). In this figure, 79 of the landslides marked 

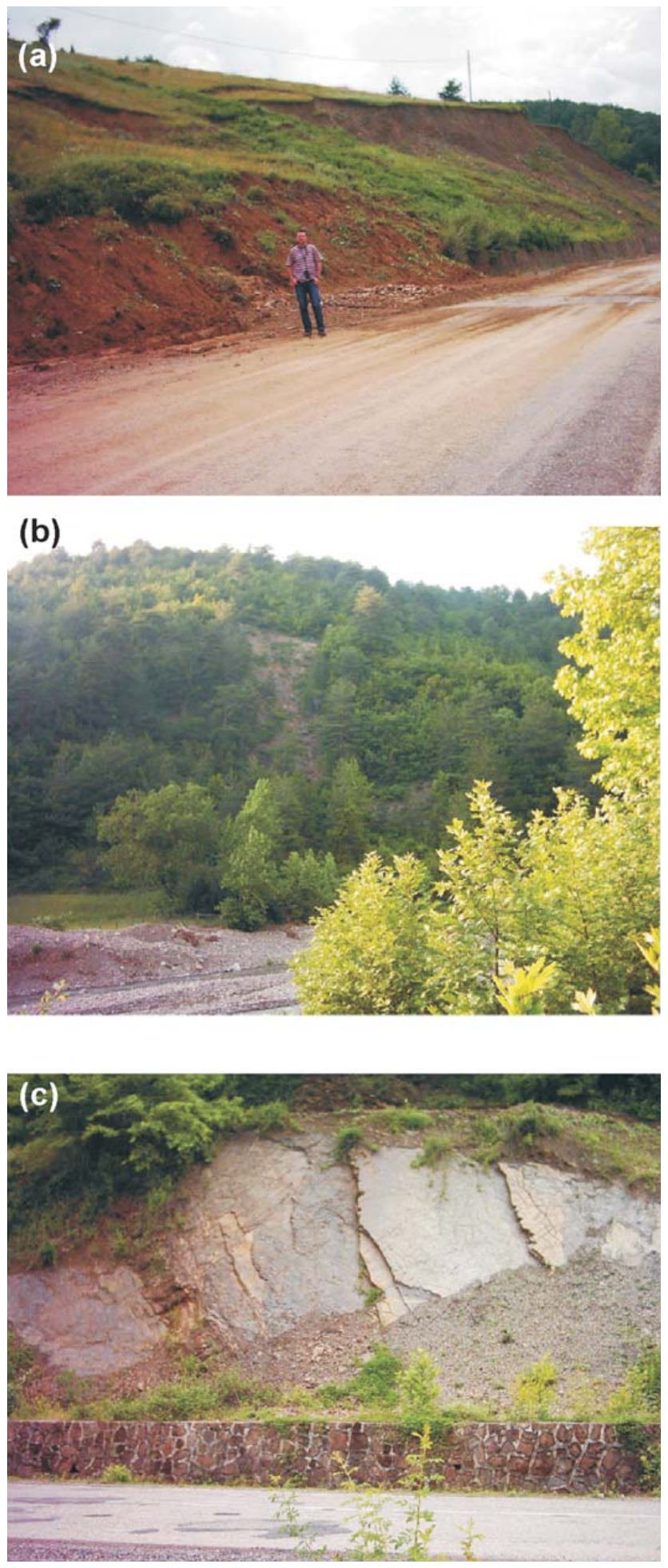

Fig. 4. Examples of landslide types mapped in the study area: (a) rotational slide; (b) earth flow; (c) translational slide.

with blue colour, located in the southwest of Kumluca and covering approximately $2.9 \mathrm{~km}^{2}$, were used for the validation stage, which will be discussed in Sect. 4. According to the landslide classification proposed by Dikau et al. (1996), 55\% $(n=173)$ of the landslides in the study area were classified as rotational slides, $44 \%(n=133)$ as soil flows, and 3\% $(n=11)$ as translational slides. Typical views of the landslides are given in Fig. 4.

In order to evaluate the landslide characteristics, at the first stage, the landslide inventory map was converted to a grayscale image using Idrisi Kilimanjaro and a grid resolution of $25 \mathrm{~m} \times 25 \mathrm{~m}$, having the same features with the DEM obtained from General Command of Mapping. This coverage contained 1409798 pixels in 1261 columns and 1118 rows. Of these, 920967 pixels belong to the Ulus formation for which subsequent analyses are focused. 17576 pixels, 4512 of which belonging the validation data set, were in areas of landslides and were reassigned the pixel value of one. All other pixels, were given a value of zero thereby producing a Boolean layer representing the landslide database used for the study.

Although there are several geological, topographical, and/or environmental parameters that can be used to produce landslide susceptibility maps, selection of these parameters depends on several factors such as data availability, data quality, size of the study area, scale of the work, user experience etc. For this study, six input parameters (slope angle, slope aspect, elevation, topographic shape, wetness index, and vegetation index) were produced and taken into consideration for the landslide susceptibility analyses. All the aforementioned parameter map coverages are shown in Figs. 5a, $\mathrm{b}, \mathrm{c}, \mathrm{d}, \mathrm{e}$, and $\mathrm{f}$.

Except for the vegetation index, all parameter maps were produced from a DEM of the study area. The vegetation index was produced using ASTER (Advanced Spaceborne Thermal Emission and Reflection Radiometer) (14 Spectral Band, Level 1B) satellite imagery. To do this, NDVI (Normalized Difference Vegetation Index) values (Rouse et al., 1974), representing the vegetation cover, were calculated for the study area using Idrisi Kilimanjaro. NDVI is one of the slope-based vegetation index models which are widely used to generate vegetation indices. NDVI is an index derived from reflectance measurements in the red and nearinfrared portions of the electromagnetic spectrum describing the relative amount of photosynthetically active green biomass present at the time of imagery.

Although the effects of groundwater on slope instability was emphasized by many different studies (e.g. Carrara et al., 1991; Juang et al., 1992; Pachauri and Pant, 1992; Maharaj, 1993; Mejia-Navarro and Wohl, 1994; Gokceoglu and Aksoy, 1996; Guzzetti et al., 1999; Fernandez et al., 1999; Nagarajan et al., 2000; Uromeihy and Mahdavifar, 2000), representative groundwater data could not be obtained for the study area. Some observations were made based on Anbalagan's (1992) water condition classification system. However, this is not considered an objective way to characterize the water conditions. A DEM-based wetness index, or compound topographic index (CTI) (Moore et al., 1988), was used to represent the spatial distribution of water flow across the study area. The wetness index represents a theoretical measure of the accumulation of flow at any point within a 

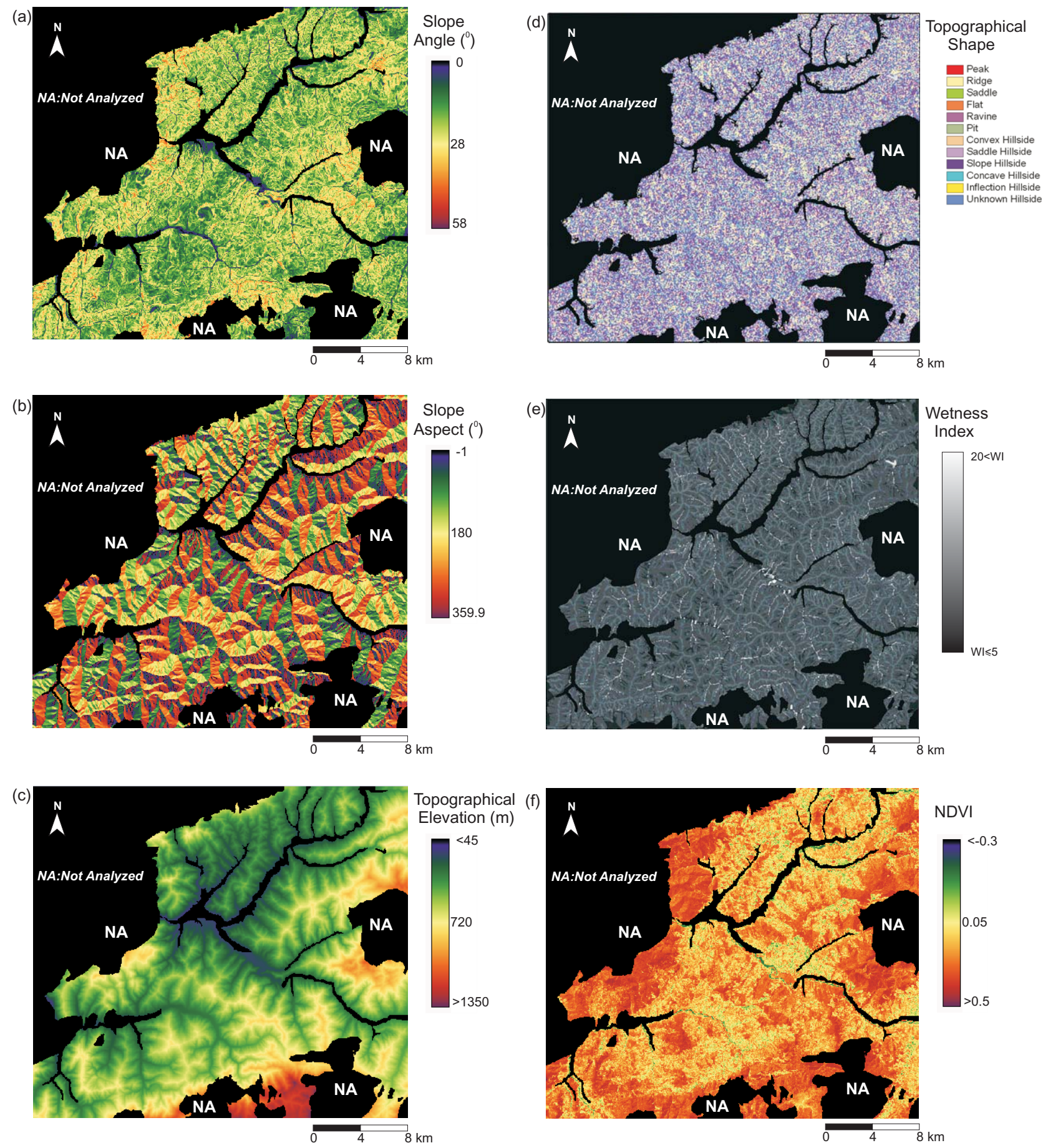

Fig. 5. Parameter maps considered in the study: (a) slope angle; (b) slope aspect; (c) topographical elevation; (d) topographical shape; (e) wetness index; (f) normalized difference vegetation index.

river basin. Thus, a more objective quantitative approach is used. The wetness index was calculated using the expression:

$w=\ln (A s / \tan \beta)$

where $w$ is the wetness index, As is the specific catchment area and $\beta$ is slope angle. Map Window (Release 2.7) (EMRC, 2002) was used to calculate wetness index.
In order to evaluate the relation between the topographical shape and the landslides, Toposhape module of Idrisi Kilimanjaro was used. It gives a kind of surface shape classification consisting of 11 possible topographic features based on DEM. This classification is based on polynomial surface fitting of each $3 \times 3$ pixel area. Eigenvalues are solved from the second directional derivative of the partial quartic equation for a central pixel of a $3 \times 3$ neighborhood. The eigenvalues 
hold the information for the magnitude of rate of change of a tangent line along the mathematically described curve in the aspect direction of the pixel and in the direction orthogonal to aspect (Eastman, 2003).

Lithology, one of the most important geological factors controlling landslide occurrence, was not considered as an input parameter in this study. Although lithology controls the type and mechanism of the landslide in general, it was considered a constant because of the existence of landslides in only one lithologic unit, the Ulus formation. However, it can be concluded that lithology has an indirect effect on the analyses because the boundaries of the Ulus formation define the area of concern.

To evaluate characteristics of landslides, landslide inventory and parameter maps were analyzed together similar to the work performed by Ercanoglu and Gokceoglu (2004). Firstly, two layers such as lithology and landslide existence were examined. If the lithology was Ulus formation and the pixel was exposed to a landslide (pixel value $=1$ ), the value of the pixels were recorded and taken into consideration during the training stage for further analyses. Areal distribution of the parameters and their subgroups in the study area and landslide areas were extracted from the appropriate GIS layers and shown in Figs. 6a, b, c, d, e, and f.

The distribution of landslided pixels in Fig. 6 suggests that most of the landslides in the study area occur in the gentle slopes rather than the steep slopes. This situation is related to the cause of accumulation of the soil material coming from the upper resistant rocks by weathering or erosional processes associated with the possible saturation of soil by low groundwater level in the gentle slopes. Landslide occurrence seems to be possible in almost every slope aspect, but, slopes facing to the West seem to be more susceptible to landsliding. Landslides occur in areas with lower topographical elevations, which are covered by the soils derived from the Ulus formation. With respect to the topographical shapes convex hillsides appear to be more susceptible to landsliding. However, there are also considerably landslided pixels corresponding to concave hillsides. Since the denominator of the equation of Wetness Index (Eq. 1) is related to slope angle, it is clear that the lower slope angle, the greater wetness index for the same catchment area. Thus, it can be concluded that the wetness index values between 15 and 20 are in accordance with the slope angle interval of $10^{\circ}-30^{\circ}$ which are also abundant in both the study area and the landslided pixels. Most of the study area generally contains positive NDVI values and is covered by photosynthetically active forests or other vegetation biomasses. According to the NDVI values, landslides in the region generally occur in the bare soils and grasslands of the study area.

\section{Methodology}

When applying models for susceptibility evaluation, it is very important to define the criteria controlling the degree of susceptibility to landslides. In general, the criteria depend both on real geo-environmental conditions as well as the purpose of mapping. In addition, sometimes engineering judgments have to be applied to establish the real criteria for particular geo-environments (Abdolmasov and Obradovic, 1997). However, selection of appropriate parameters, which are not only meaningful, but also necessary for special cases, is the most important task in any methodology development. Generally speaking, preparing a landslide susceptibility map for any region involves the following stages:

1. Preparation of landslide database/inventory.

2. Selection of the parameters.

3. Quantitative or qualitative classification of the parameters.

4. Assigning weights to the parameters subjectively or objectively.

5. Evaluating the susceptibility degree for each parameter.

6. Susceptibility mapping.

As highlighted by the steps, uncertainty exists in almost every stage of landslide susceptibility modeling. It is well recognized that the various factors contributing to landslides in a region are complexly interrelated (Jade and Sarkar, 1993) and the relationships between these factors and the landslides are nonlinear in nature. Hence, improvement of existing methods or the application of new techniques, which are concerned with or represent the nonlinearity of landslide susceptibility assessments, is indispensable. Under such conditions, use of nonlinear models that can be applied to the multisource data analysis and classification with respect to landslide assessments may be more suitable. Therefore, ANN seems to be one of the most effective ways to cope with these challenges.

Generally speaking, ANN have a great advantage in dealing with problems in which: (i) many factors influence process and result; (ii) the understanding of the process is inadequate or complex; and (iii) there are experimental or field data available (Huang and Wanstedt, 1998). However, there are also disadvantages for the utilization of ANN such as proneness to overfitting, a great deal of computational burden, data mining, and lack of explicit knowledge. Furthermore, one of the most important disadvantages in using ANN is its black-box nature since the relations between the input and output parameters are not developed by the user or expert. ANNs adapt the given data to the network themselves during the calculation stages until the network has achieved an acceptable level.

ANNs constitute a class of systems which are inspired by the biological functioning of the human brain (Fig. 7a). Thus, they have the capability to learn similar to the human beings. Most ANNs have at least three layers and contain different processing units known as neurons which are connected by the weights (Fig. 7b). The conventional explanation of what these layers do is that the input layer distributes the input patterns throughout the network, the output layer generates an 
STUDY AREA
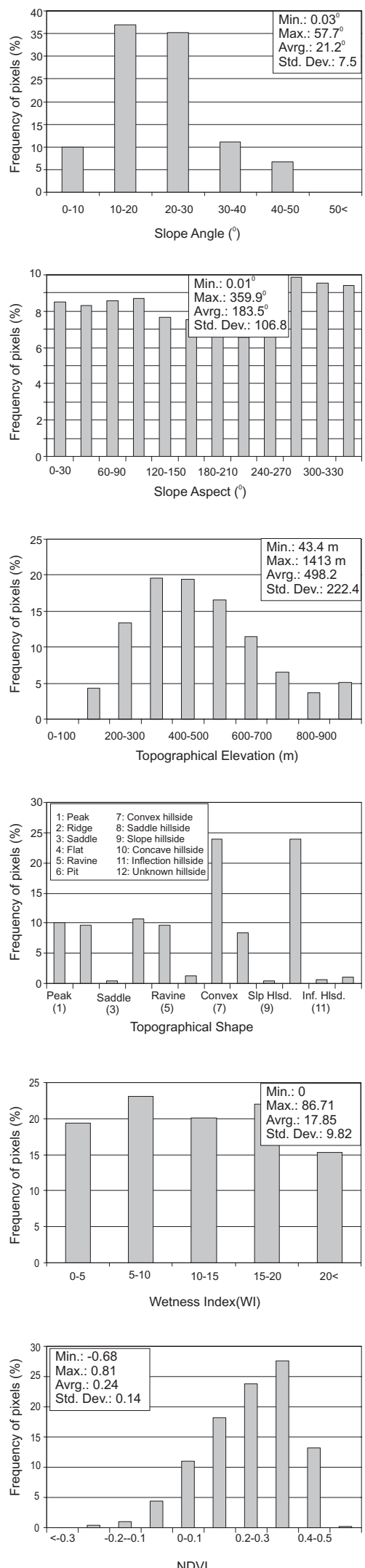

LANDSLIDED AREAS

(a)

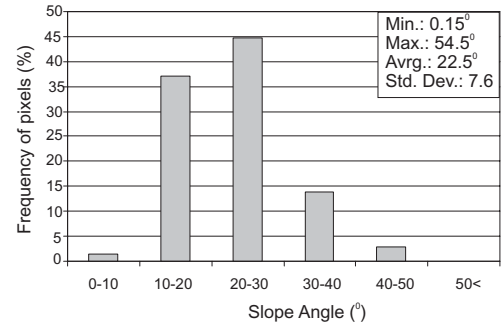

(b)

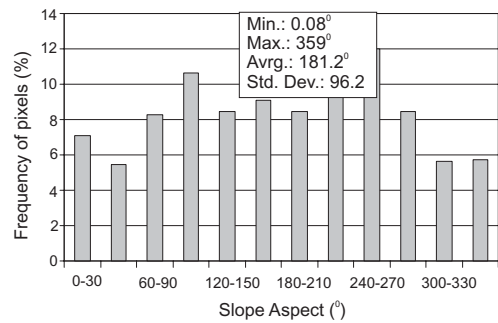

(c)

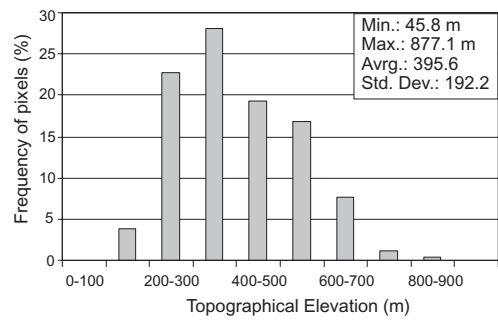

(d)

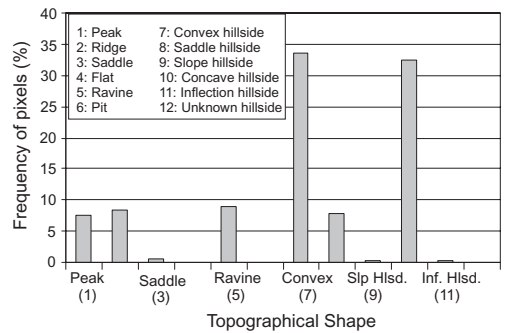

(e)

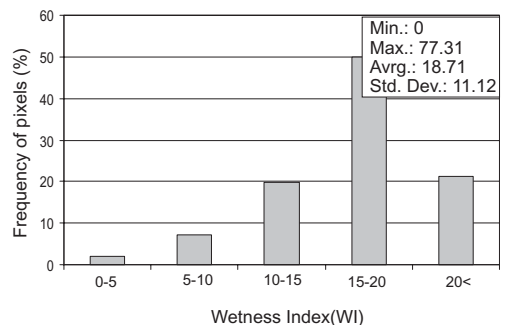

(f)

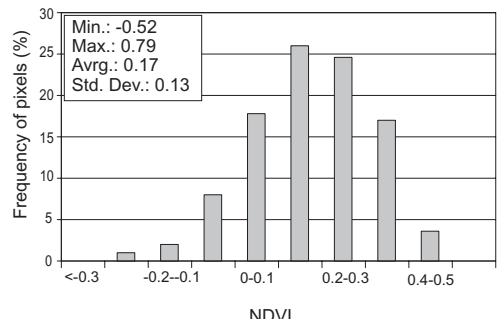

Fig. 6. Areal distribution of pixels in the study area and landslided areas: (a) slope angle; (b) slope aspect; (c) topographical elevation; (d) topographical shape; (e) wetness index; (f) normalized difference vegetation index. 
(a)

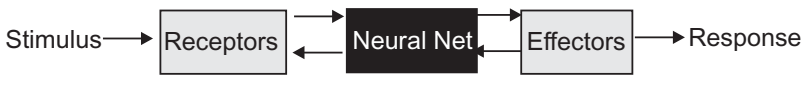

(b)

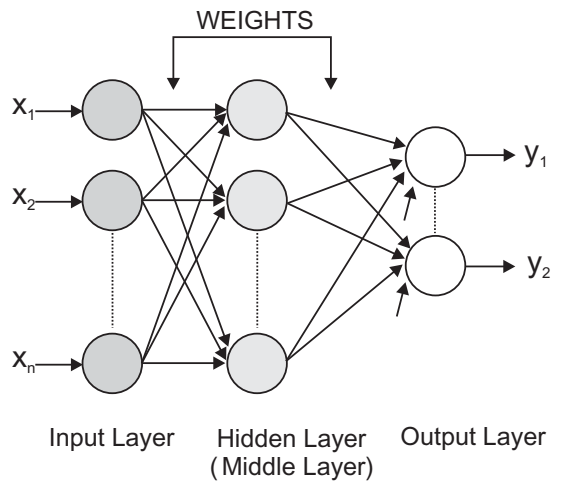

Fig. 7. (a) Generalized illustration of the human nervous system (after Haykin, 1999); (b) general structure of an artificial neural network.

appropriate response, and the hidden (middle) layer acts as a collection of feature detectors. The output layer can then construct an appropriate output pattern based on the particular combination of features the middle layer has detected. Mathematical concepts and technical aspects of ANNs are beyond the objectives of this study, and can be found in various publications in the literature (e.g. Rumelhart et al., 1986; Caudill and Buttler, 1992; Ross, 1995; Huang and Wanstedt, 1998; Haykin, 1999).

\subsection{ANN analyses}

In this study, NeuralNet module of Idrisi Kilimanjaro (Eastman, 2003) was used to produce a landslide susceptibility map of the study area. The NeuralNet module uses BP (back propagation) learning algorithm (Rumelhart et al., 1986). This algorithm is also known as the generalized delta rule. It defines rules for propagating the network error back from network output to network input units and adjusting network weights along with the back propagation. This algorithm operates by searching an error surface, defined as a function of the network weights, using a gradient descent method to locate the weight combinations with minimum error. One of its main advantages is that it is distribution free. In other words, no underlying model is assumed for the multivariate distribution of the class specific data in feature space. As mentioned before, one of the most important advantages of utilization of ANNs is its ability to learn performed by training stage. In this stage, error is back propagated to the neural network and used to adjust the weights. It is repeated until the overall error value falls within a specified tolerance limit. This process is known as the training stage of the neural network. The network learns by adjusting the weights in each processing element throughout the network. Thus, the different weights in the neural network connecting the different elements are updated and can approximate the final output more closely. Finally, a testing data set is used to verify the performance of the neural network. During this stage, ANN does not adjust itself, but simply generates an output, which the user compares with the desired output.

Before the training stage of the analyses, it was attempted to express the effects of input parameters and their subgroups on landslide occurrence. To perform this objectively, the Statistical Index (Wi) (Van Westen, 1997) approach, based on the frequency analysis method, was employed. It simply defines the importance of a parameter subgroup on landslide occurrence according to spatial distribution of the pixels of the considered parameters and the lanslided pixels. $W i$ is expressed as in the following equation:

$W i=\left[\left(N_{\text {pix }}(S i) / N_{\text {pix }}(N i)\right) /\left(\left(\Sigma N_{\text {pix }}(S i) / \Sigma N_{\text {pix }}(N i)\right](2)\right.\right.$

where $N_{\text {pix }}(\mathrm{Si})$ is the number of pixels exposed to landslides for a subgroup of a parameter, $N_{p i x}(N i)$ is the total number of pixels for the related parameter. $W i$ values were calculated according to the pixel values tabulated at Table 1 . Then, these values were expressed and normalized in $[0,1]$ interval for each parameter and their subgroups to represent parametric importances on landslide occurrence.

These values were then assigned to each parameter map. Thus, the parameter maps with pixel values representing landslide susceptibility based on the normalized Wi values were derived from the input layers shown in Figs. 8a, b, c, d, $\mathrm{e}$, and $\mathrm{f}$. These maps were used as the six input parameters for the ANN architecture used in the study.

The design stage of an ANN is very important because the performance of the ANN can be affected by such design parameters as the number of hidden nodes, the quantity of training and testing data, the momentum coefficient, learning rate, the number of training cycles, and initial weights. It is possible to cope with this problem by using an iterative trial-error approach; however, this may take a lot of time and cause confusing results such as overfitting or underfitting. Idrisi Kilimanjaro calculates most of the ANN design parameters automatically according to the data structure. However, the user can optionally choose and change parameters during the analyses.

For the training stage, both raster and vector data can be used. In this study, raster data (i.e. the inventory map) was used. Based on these data, the number of hidden layer was calculated by Idrisi Kilimanjaro as 3 . The default values provided by the software were selected for the learning rate and momentum factor. Learning rate is a positive constant controlling the amount of adjustment of the connecting weights. If it is too small, training stage may become overestimated and time consuming. If the learning rate is too large, underestimation may occur for the training stage. The default value proposed by the software is $0.1-0.2$ and was chosen 0.2 for this study. Another parameter is momentum factor. This value prevents divergence problems during the search for the 
Table 1. Landslide database showing the characteristics of the landslides according to the considered parameters.

\begin{tabular}{|c|c|c|c|c|}
\hline Group No & Parameter & $\begin{array}{c}\text { Number of } \\
\text { Landslided Pixels }\end{array}$ & $\begin{array}{c}\text { Number of Pixels } \\
\text { Belonging } \\
\text { Parameter Subgroup }\end{array}$ & $\begin{array}{r}\text { Normalized } \\
W i \text { Values }\end{array}$ \\
\hline \multicolumn{5}{|c|}{ Slope Angle, $S A\left(^{\circ}\right)$} \\
\hline 1 & $0 \leq \mathrm{SA} \leq 10$ & 262 & 91929 & 0.12 \\
\hline 2 & $10<\mathrm{SA} \leq 20$ & 6510 & 340986 & 0.78 \\
\hline 3 & $20<\mathrm{SA} \leq 30$ & 7862 & 323523 & 1 \\
\hline 4 & $30<\mathrm{SA} \leq 40$ & 2430 & 103026 & 0.97 \\
\hline 5 & $40<\mathrm{SA} \leq 50$ & 494 & 61336 & 0.33 \\
\hline 6 & $50<\mathrm{SA}$ & 18 & 167 & 0.01 \\
\hline \multicolumn{5}{|c|}{ Slope Aspect, $S A S\left(^{\circ}\right)$} \\
\hline 1 & $0<\mathrm{SAS} \leq 30$ & 1241 & 78576 & 0.50 \\
\hline 2 & $30<\mathrm{SAS} \leq 60$ & 964 & 76324 & 0.40 \\
\hline 3 & $60<\mathrm{SAS} \leq 90$ & 1455 & 78881 & 0.59 \\
\hline 4 & $90<\mathrm{SAS} \leq 120$ & 1873 & 80224 & 0.75 \\
\hline 5 & $120<\mathrm{SAS} \leq 150$ & 1483 & 70324 & 0.67 \\
\hline 6 & $150<\mathrm{SAS} \leq 180$ & 1592 & 69574 & 0.73 \\
\hline 7 & $180<\mathrm{SAS} \leq 210$ & 1480 & 62594 & 0.75 \\
\hline 8 & $210<\mathrm{SAS} \leq 240$ & 1890 & 60333 & 1 \\
\hline 9 & $240<$ SAS $\leq 270$ & 2114 & 79229 & 0.85 \\
\hline 10 & $270<$ SAS $\leq 300$ & 1483 & 90614 & 0.52 \\
\hline 11 & $300<\mathrm{SAS} \leq 330$ & 990 & 87761 & 0.36 \\
\hline 12 & $330<$ SAS $\leq 360$ & 1011 & 86533 & 0.37 \\
\hline \multicolumn{5}{|c|}{ Topographical Elevation, TEL $(\mathrm{m})$} \\
\hline 1 & $0 \leq \mathrm{TEL} \leq 100$ & 0 & 463 & 0 \\
\hline 2 & $100<\mathrm{TEL} \leq 200$ & 680 & 38896 & 0.54 \\
\hline 3 & $200<\mathrm{TEL} \leq 300$ & 4012 & 123192 & 1 \\
\hline 4 & $300<\mathrm{TEL} \leq 400$ & 4940 & 181072 & 0.84 \\
\hline 5 & $400<\mathrm{TEL} \leq 500$ & 3395 & 179137 & 0.58 \\
\hline 6 & $500<\mathrm{TEL} \leq 600$ & 2951 & 152292 & 0.59 \\
\hline 7 & $600<\mathrm{TEL} \leq 700$ & 1351 & 105120 & 0.39 \\
\hline 8 & $700<\mathrm{TEL} \leq 800$ & 186 & 60343 & 0.09 \\
\hline 9 & $800<\mathrm{TEL} \leq 900$ & 61 & 34021 & 0.05 \\
\hline 10 & $900<$ TEL & 0 & 46431 & 0 \\
\hline \multicolumn{5}{|c|}{ Topographical Shape, TS } \\
\hline 1 & Peak & 1348 & 92375 & 0.55 \\
\hline 2 & Ridge & 1474 & 88322 & 0.63 \\
\hline 3 & Saddle & 98 & 3975 & 0.92 \\
\hline 4 & Flat & 0 & 99178 & 0 \\
\hline 5 & Ravine & 1577 & 87999 & 0.67 \\
\hline 6 & Pit & 0 & 10897 & 0 \\
\hline 7 & Convex Hillside & 5885 & 220195 & 1 \\
\hline 8 & Saddle Hillside & 1392 & 77871 & 0.67 \\
\hline 9 & Slope Hillside & 60 & 4337 & 0.50 \\
\hline 10 & Concave Hillside & 5716 & 220446 & 0.97 \\
\hline 11 & Inflection Hillside & 26 & 5385 & 0.18 \\
\hline 12 & Unknown Hillside & 0 & 9987 & 0 \\
\hline \multicolumn{5}{|c|}{ Wetness Index, WI } \\
\hline 1 & $\mathrm{WI} \leq 5$ & 328 & 178978 & 0.04 \\
\hline 2 & $5<\overline{\mathrm{W}} \mathrm{I} \leq 10$ & 1275 & 212532 & 0.14 \\
\hline 3 & $10<\mathrm{WI} \leq 15$ & 3461 & 185175 & 0.43 \\
\hline 4 & $15<\mathrm{WI} \leq 20$ & 8785 & 203194 & 1 \\
\hline 5 & $20<\mathrm{WI}$ & 3727 & 141088 & 0.61 \\
\hline \multicolumn{5}{|c|}{ Normalized Difference Vegetation Index, NDVI } \\
\hline 1 & $\mathrm{NDVI} \leq-0.3$ & 0 & 343 & 0 \\
\hline 2 & $-0.3<\mathrm{NDVI} \leq-0.2$ & 181 & 3237 & 1 \\
\hline 3 & $-0.2<\mathrm{NDVI} \leq-0.1$ & 353 & 8904 & 0.71 \\
\hline 4 & $-0.1<\mathrm{NDVI} \leq 0$ & 1399 & 41204 & 0.61 \\
\hline 5 & $0<\mathrm{NDVI} \leq 0 . \overline{1}$ & 3142 & 102051 & 0.55 \\
\hline 6 & $0.1<\mathrm{NDVI} \leq 0.2$ & 4556 & 168335 & 0.48 \\
\hline 7 & $0.2<\mathrm{NDVI} \leq 0.3$ & 4308 & 218542 & 0.35 \\
\hline 8 & $0.3<\mathrm{NDVI} \leq 0.4$ & 2999 & 254436 & 0.21 \\
\hline 9 & $0.4<\mathrm{NDVI} \leq 0.5$ & 638 & 122146 & 0.09 \\
\hline 10 & $0.5<\mathrm{NDVI}$ & 0 & 1769 & 0 \\
\hline
\end{tabular}



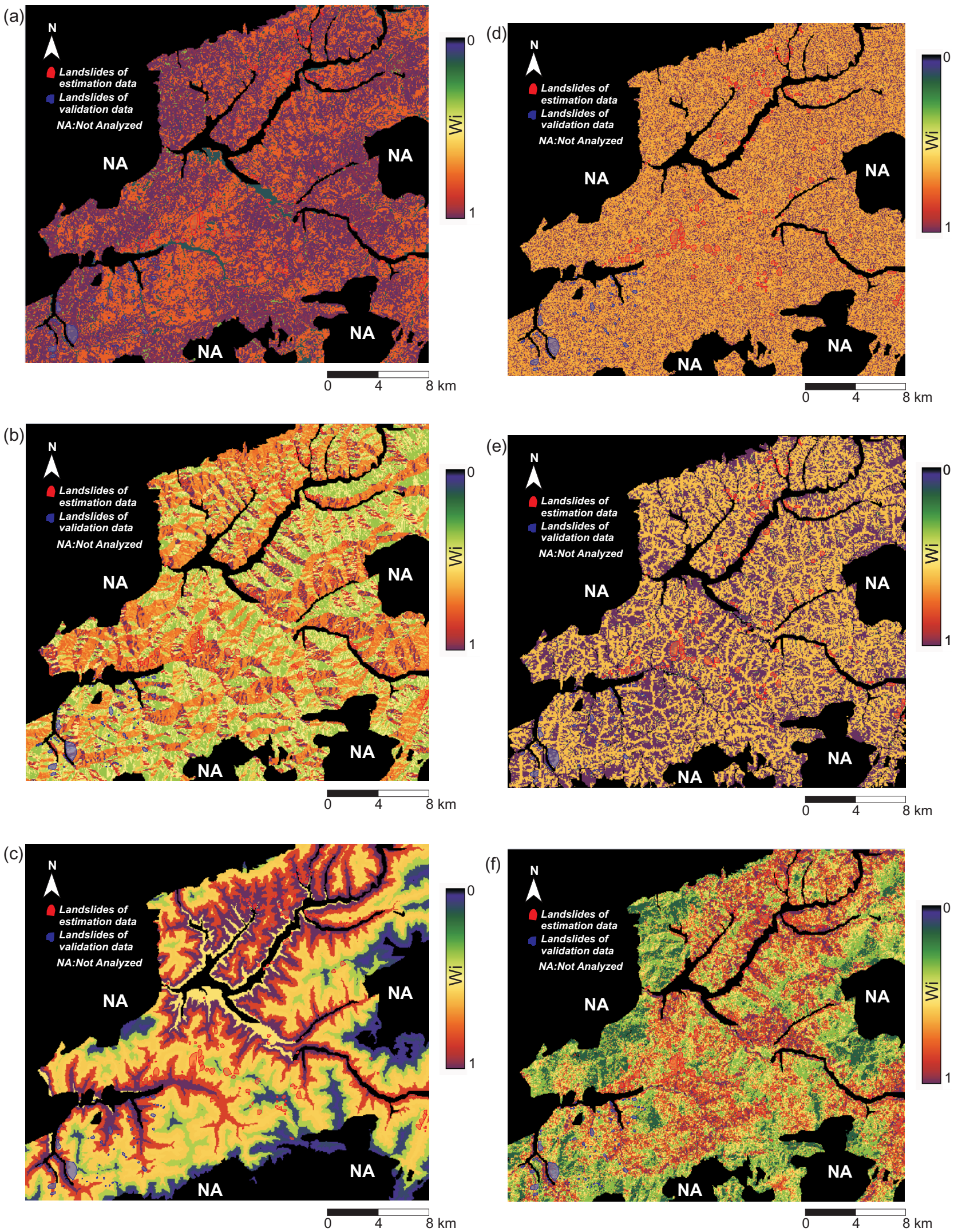

Fig. 8. Schematic representation of normalized Statistical Index values representing landslide susceptibility for (a) slope angle; (b) slope aspect; (c) topographical elevation; (d) topographical shape; (e) wetness index; (f) normalized difference vegetation index. 


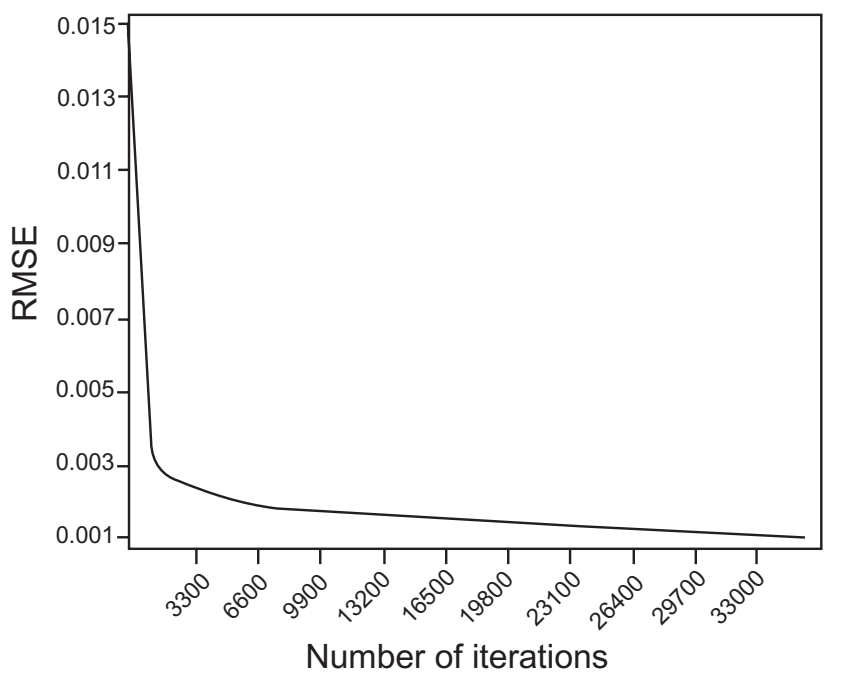

Fig. 9. Graph showing the RMSE value changes versus number of iterations.

minimum value on the error surface and is used to accelerate the convergence. It was recommended that this factor be between 0.5 and 0.6 and was chosen 0.6. Root Mean Square Error (RMSE) is used to stop the training when RMSE drops below the specified value (0.001 was selected for this study) for the training data. RMSE is expressed in the formula given below:

$\operatorname{RMSE}=\sqrt{(1 / N) * \sum_{\mathrm{i}=1}^{\mathrm{N}}\left(\mathrm{y}-\mathrm{y}^{\prime}\right)^{2}}$

where, $y$ is the target output, $y^{\prime}$ is the predicted output, and $N$ is the number of data. Closeness of RMSE to 0 indicates a good relationship between target and predicted values. Idrisi Kilimanjaro also adjusts the weights and stores the number of iterations during the RMSE calculation. This process (i.e. the training stage) is continued until the specified RMSE value is obtained (33 979 iterations were used for the study) (Fig. 9). According to these analyses, ANN produced $86.3 \%$ overall accuracy with testing data, and this result was considered satisfactory.

The final step of ANN analysis was preparation of the landslide susceptibility map. To achieve this, the trained and tested ANN architecture was applied to the derivative data sets and the final landslide susceptibility map of the study area was produced (Fig. 10a). According to this map, 26.5\% of the study area was classified as susceptible to landslides.

\subsection{Validation of the landslide susceptibility map}

In order to evaluate the performance of the landslide susceptibility model, the pixel values of the inventory and final susceptibility model were correlated in three different ways such as (i) a measure of goodness of fit, (ii) a similarity approach, and (iii) an independent validation strategy similar to the procedure performed by Zêzere et al. (2004).

The first one is simply the correlation between the target and predicted output values for the landslide existence. In (a)

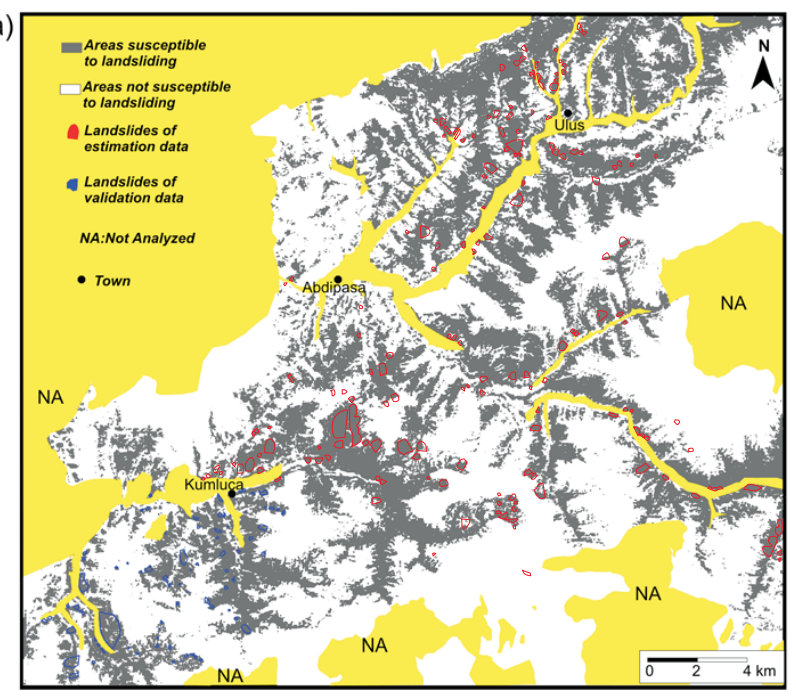

(b)

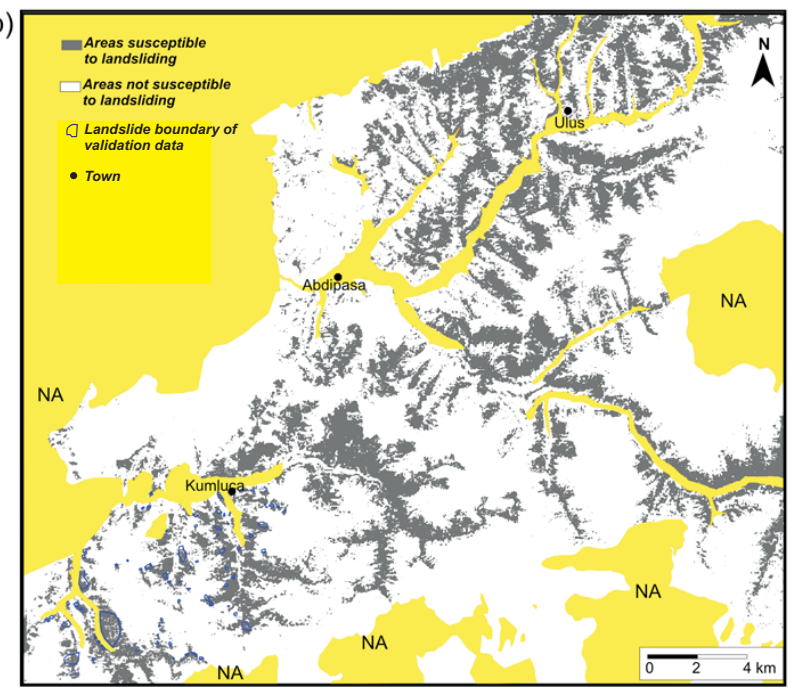

Fig. 10. (a) Landslide susceptibility map of the study area; (b) landslide susceptibility map produced by using estimation landslide data set.

other words, the landslide inventory and the final landslide susceptibility model were correlated according to the existence of landslide pixels (1) or not (0). Based on this approach, $87.2 \%$ of existing landslide pixels (1) were classified as correctly, while the rest of the landslide pixels $(12.8 \%)$ was classified as incorrectly.

The second evaluation approach applied the cosine amplitude method, which is one of the most commonly used similarity methods (Zadeh, 1975). The cosine amplitude method calculates $r_{i j}$ value (strength of relation) by the following equation and range of $r_{i j}$ values varies from 0 to 1 $\left(0 \leq r_{i j} \leq 1\right)$ :

$r_{i j}=\frac{\left[\sum_{k=1}^{m} x_{i k} \times x_{j k}\right]}{\sqrt{\left(\sum_{k=1}^{m} x_{i k}^{2}\right) \times\left(\sum_{k=1}^{m} x_{j k}^{2}\right)}}$ 


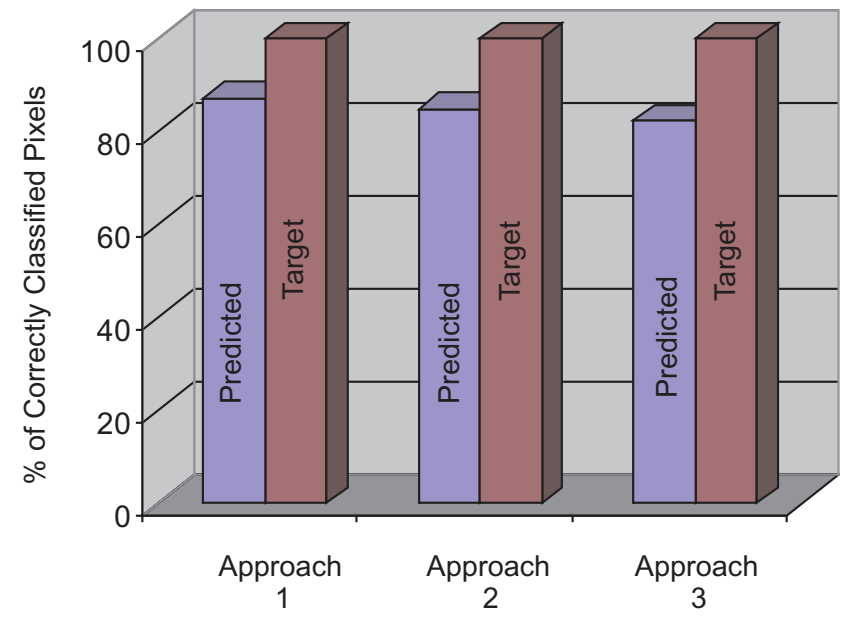

Fig. 11. Histogram showing the validation of the performance of the landslide susceptibility map using 3 different approaches.

According to this equation, values of $r_{i j}$ close to 0 indicate dissimilarity, while values of $r_{i j}$ close to 1 indicate similarity between the two data sets. To calculate the $r_{i j}$ value, the landslide inventory and final landslide susceptibility map (see Fig. 10a) were used. This approach indicated high performance results as the calculated $r_{i j}$ value was 0.85 which is close to 1 .

In order to evaluate the validation of the previously produced landslide susceptibility map given in Fig. 10a, finally, an independent validation strategy was also performed. To do this, landslide data set was divided in two groups such as estimation data set (pixels of 238 cases, landslides in red, see Fig. 3) and validation data set (pixels of 79 cases, landslides in blue, see Fig. 3). This distinction was made based on the criterion of landslide locations, and landslides in the SW of Kumluca were selected as the validation data set. The estimation data set was re-subjected to the same procedures mentioned before to produce a new landslide susceptibility map without changing any ANN architecture features used previously. Finally, the new landslide susceptibility map was obtained using the estimation landslide data (Fig. 10b). According to this map, 3725 of the pixels $(82.5 \%)$ of the 4512 , covered by the validation data set, were classified as correctly, while the $17.5 \%$ of those were classified as incorrectly. The summary and the schematic representations of the performances of these approaches can be seen in Fig. 11. Consequently, it can be concluded that all the 3 approaches suggest good agreement between the mapped landslides and the areas classified as susceptible to landslides.

\section{Results and conclusions}

The following results and conclusions can be drawn from the present study:

Landslide susceptibility of a selected region in West Black Sea Region of Turkey was mapped using an ANN system. Idrisi Kilimanjaro software, employing a back propagation learning algorithm for the ANN system, was used. Slope angle, slope aspect, topographical elevation, topographical shape, wetness index, and vegetation index parameters were used as inputs to the ANN system. Three hundred and seventeen landslides of three different types, covering approximately $2 \%$ of the study area, were mapped through field work and aerial photo interpretation.

Lithology was neglected as an input parameter during the landslide susceptibility analysis because the landslides in the study area were found only one geological unit, the Ulus formation. Although it is not easy to identify the causes of landslides exactly, topographical elevation was found to be the most important effect on landslide occurrence in the study area according to the assessed ANN weight changes. In contrast to prevailing thought, gentle slopes and low topographical elevations were found as more susceptible to landsliding than steep slopes and high topographical elevations. The second important parameter contributing the landslide occurrence was found as the slope angle covering particularly gentle slopes, and was the most important parameter in the previous studies (Ercanoglu and Gokceoglu, 2002, 2004; Ercanoglu et al., 2004) carried out in close vicinity of the study area. According to the landslide database, slopes facing to the West have higher landslide susceptibility. However, landslide occurrence was found to be possible in almost every slope aspect. Concave and/or convex shaped slopes are more susceptible to landslides than the other topographical shape types. Wetness index values were used to present water condition in the study area, and represent the features that are in accordance with the other topographical parameters in the landslide database. Generally, landslides in the study area occurred in bare soils and grasslands, although there were also many landslides in densely vegetated areas. This situation was concluded as the vegetation cover has no favorable and/or important effect on landslide occurrence.

Based on the resulting landslide susceptibility map, $26.5 \%$ of the study area was classified as susceptible to landslides. Of those areas where landslides have previously occurred, $87.2 \%$ were correctly classified by the ANN. In addition, $r_{i j}$ value was calculated as 0.85 , which shows high performance with respect to the similarity approaches. Although these two approaches gave good results, an independent validation strategy was also applied to validate the produced map. According to this map, $82.5 \%$ of the validation data set was classified as correctly. When considering all these results, the produced susceptibility map was considered as satisfactory.

Due to its dynamic, flexible and nonlinearity-adaptable features, ANNs have an advantage of being able to deal with complex input-output relationships. In addition, their nonparametric features provide the ability to represent the nonlinearities of the environment. However, particularly its black box features, when using an ANN architecture, engineering judgment and some expertise should be required. It is believed that the ANNs can be used as a powerful tool when different types of landslides with complex mechanisms exist (i.e. complex input-output relationships) in medium or regional scale studies, as the case of the present study. For 
example, when compared with the previous study (Ercanoglu and Gokceoglu, 2004) performed in the region and also covering some SW part of the study area, the present study showed $22 \%$ better performance, in terms of correctly classified pixels for this mutual part.

It is believed that the lack of landslide inventory and susceptibility map, rarely used in Turkey, will be satisfied at least for the study area. Resulting landslide susceptibility map provides useful information and economic benefits for the future works such as urban development and planning, engineering applications, and land-use potential planning in the region. However, it should be noted that the produced susceptibility map should not be used for the design purposes.

Acknowledgements. The author would like to thank K. T. Weber (Idaho State University) and T. Windholz (Idaho State University) for their valuable comments and criticism on the manuscript. The author would also like to thank O. Kasmer and N. T. Yuksel for their great efforts during field studies. This research is supported by the Scientific and Technical Research Council of Turkey (TUBITAK) (Project No: 103Y126).

Edited by: F. Guzzetti

Reviewed by: J. L. Zêzere and two referees

\section{References}

Abdolmasov, B. and Obradovic, I.: Evaluation of geological parameters for landslide hazard mapping, in: Proc. of Int. Symp. on Eng. Geol. and Env. (pp. 471-476), edited by: Marinos, P. G., Koukis, G. C., Tsiambaos, G. C., and Stournaras, G. C., 23-27 June 1997, Athens, Greece, Balkema, 1997.

Aleotti, P. and Chowdhury, R.: Landslide hazard assessment: summary review and new perspectives, Bull. of Eng. Geol. and Env., 58, 21-44, 1999.

Anbalagan, R.: Landslide hazard evaluation and zonation mapping in mountainous terrain, Eng. Geol., 32, 269-277, 1992.

Binaghi, E., Luzi, L., Pergalani, F., and Rampini, A.: Slope instability zonation: a comparison between certainty factor and fuzzy Dempster-Shafer approaches, Nat. Haz., 17, 77-97, 1998.

Carrara, A., Cardinali, M., Detti, R., Guzzetti, F., Pasqui, V., and Reichenbach, P.: GIS techniques and statistical models in evaluating landslide hazard, Earth Surf. Proc. and Landf., 16, 427445, 1991.

Carrara, A., Crosta, G., and Frattini, P.: Geomorphological and historical data in assessing landslide hazard, Earth Surf. Proc. and Landf., 28, 1125-1142, 2003.

Caudill, M. and Butler, C.: Understanding neural networks: computer explorations, Vol, 2, MIT Press, London, 1992.

Demir, B. and Ercan, S.: Yenice ilçesindeki heyelanlar üzerine bazıgözlemler, Türkiye 3. Ulusal Heyelan Sempozyumu Özleri Kitabı, Çukurova Üniversitesi, Adana, 16 s, (in Turkish), 1999.

Deveciler, E.: Alapl1-Bartın-Cide (B.Karadeniz) jeoloji raporu, MTA yayınları, Derleme No: 7938, 58 s, (in Turkish), 1986.

Dikau, R., Brunsden, D., Schrott, L., and Ibsen, M. L.: Landslide recognition, identification, movements and causes, John Wiley and Sons, Chchester, England, 251 p., 1996.
Duman, T. Y., Can, T., Emre, O., Kecer, M., Dogan, A., Ates, A., and Durmaz, S.: Landslide inventory of northwestern Anatolia, Turkey, Eng. Geol., 77 99-114, 2005.

Eastman, J. R.: IDRISI Kilimanjaro, guide to GIS and image processing, user's guide (Ver. 14), Clark University Press, Massachusetts, 2003.

EMRC (Environmental Management Research Center): Map Window (Ver. 2.7.21), Logan, Utah State University, 2002.

Ercanoglu, M.: Bulanık mantik ve istatistiksel yontemlerle heyelan duyarlılık haritalarının uretilmesi: Bati Karadeniz Bolgesi (Kumluca Guneyi-Yenice Kuzeyi). H.U. Fen Bil. Enst. Doktora Tezi, Ankara, 202 s. (in Turkish), 2003.

Ercanoglu, M. and Gokceoglu, C.: Assessment of landslide susceptibility for a landslide-prone area (North of Yenice, NW Turkey) by fuzzy approach, Env. Geol., 41, 720-730, 2002.

Ercanoglu, M. and Gokceoglu, C.: Use of fuzzy relations to produce landslide susceptibility map of a landslide prone area (West Black Sea Region, Turkey), Eng. Geol., 75, 229-250, 2004.

Ercanoglu, M., Gokceoglu, C., and Van Asch Th. W. J.: Landslide susceptibility zoning of North of Yenice (NW Turkey) by mutivariate statistical techniques, Nat. Haz., 32, 1-23, 2004.

Ermini, L., Catani, F., and Casagli, N.: Artificial neural networks appied to landslide susceptibility assessment, Geomorphology, 66, 327-343, 2005.

Fernandez, C. I., Del Castillo, T. F., El Hamdouni, R., and Montero, J .C.: Verification of landslide susceptibility mapping: A case study, Earth Surf. Proc. and Landf., 24, 537-544, 1999.

Gokceoglu, C. and Aksoy, H.: Landslide susceptibility mapping of the slopes in the residual soils of the Mengen region (Turkey) by deterministic stability analyses and image processing techniques, Eng. Geol., 44, 147-161, 1996.

Gomez, H. and Kavzoglu, T.: Assessment of shallow landslide susceptibility using artificial neural network in Jabonosa River nasin, Venezuela, Eng. Geol., 78, 11-27, 2005.

Guzzetti, F., Carrara, A., Cardinali, M., and Reichenbach, P.: Landslide hazard evaluation: a review of current techniques and their application in a multi-scale study, Central Italy, Geomorphology, 31, 181-216, 1999.

Guzzetti, F., Cardinali, M., Reichenbach, P., and Carrara, A.: Comparing landslides maps: a case atudy in the Upper Tiber basin, Central Italy, Env. Manag., 25, 247-263, 2000.

Haykin, S.: Neural networks: a comprehensive foundation, 2nd Edition, Prentice Hall, Upper Saddle River, New Jersey, 1999.

Huang, Y. and Wanstedt, S.: The introduction of neural network system and its applications in rock engineering, Eng. Geol., 49, 253-260, 1998.

Jade, S. and Sarkar, S.: Statistical models for slope instability classification, Eng. Geol., 36, 91-98, 1993.

Juang, C. H., Lee, D. H., and Sheu, C.: Mapping slope failure potential using fuzzy sets, Jrnl. of Geotech. Eng. Div., ASCE, 118, 475-493, 1992.

Lee, C. F., Ye, H., Yeung, M. R., Shan, X., and Chen, G.: AIGISbased methodology for natural terrain landslide susceptibility mapping in Hong Kong, Episodes, 24, 150-179, 2001.

Lee, S., Ryu, J. H., Lee, M. J., and Won, J .S.: Use of an artificial neural netwok for analysis of the susceptibility to landslides at Boun, Korea, Env. Geol., 44, 820-833, 2003.

Maharaj, R.: Landslide processes and landslide susceptibility analysis from an upland watershed: A case study from St. Andrew, Jamaica, West Indies, Eng. Geol., 34, 53-79, 1993.

Mejia-Navarro, M. and Wohl, E. E.: Geological hazard and risk evaluation using GIS: methodology and model applied to 
Medellin, Colombia, Bull. of Assoc. of Eng. Geol., XXXI (4), 459-481, 1994.

Moore, I. D., O'Loughlin, E. M., and Burch, G. J.: A contour-based topographic model for hydrological and ecological applications, Earth Surf. Proc. and Landf., 14, 305-320, 1988.

Nagarajan, R., Roy, A., Vinod Kumar, R., Mukherjee, A., and Khire, M. V.: Landslide hazard susceptibility mapping based on terrain and climatic factors for tropical monsoon regions, Bull. of Eng. Geol. and Env., 58, 275-287, 2000.

Pachauri, A. K. and Pant, M.: Landslide hazard mapping based on geological attributes, Eng. Geol., 32, 81-100, 1992.

Ross, T. J.: Fuzzy logic with engineering applications, Mc-GrawHill, New Mexico, 1995.

Rouse, J. W. Jr., Haas, R., H., Deering, D. W., Schell, J. A., and Harlan, J. C.: Monitoring the Vernal Advancement and Retrogradation (Green Wave Effect) of Natural Vegetation, NASA/GSFC Type III Final Report, Greenbelt, 1974.

Rumelhart, D. E., Hinton, G. E., and Williams, R. J.: Learning internal representations by error propagation, in: Parallel Dist. Proc., edited by: Rumelhart, D. E., and McClelland, J. L.,, Cambridge, 318-362, 1986.

Schuster, R.: Socioeconomic significance of landslides, in: Landslides: Investigation and Mitigation: Special Report, edited by: Turner, A. K. and Schuster, R. L., vol. 247, National Academic Press, Washington, DC, 12-36, 1996.
Temiz, N.: Bati Karadeniz bolgesi (Bartin, Karabuk, Zonguldak yorelerinde) kutle hareketlerinin ve bunlarıdenetleyen jeolojik ve morfolojik ozelliklerinin CBS ve Uzaktan Algılama yontemi ile arastirilmasi, H.U. Fen Bil. Enst. Jeo. Muh. Bol. Anabilim Dali, Yuk. Muh. Tezi, Ankara, 90 s. (in Turkish), 2000.

Timur, E., Aksay, A., and Celik, B.: Zonguldak F-28 paftası1/100 000 ölçekli jeoloji haritası, MTA Gn. Md., Jeoloji Etüdleri Dairesi, (in Turkish), 1997.

Uromeihy, A. and Mahdafivar, M. R.: Lanslide hazard zonation of Khorshrostam area, Iran, Bull. of Eng. Geol. and Env., 58, 207213, 2000.

Van Westen, C. J.: Statistical landslide hazard analysis, ILWIS 2.1 for Windows application guide, ITC Publication, Enschede, 7384, 1997.

Yesilnacar, E. and Topal, T.: Landslide susceptibility mapping: a comparison of logistic regression and neural networks methods in a medium scale study, Hendek region (Turkey), Eng. Geol., 79, 251-266, 2005.

Zadeh, L. A.: The concept of a linguistic variable and its application to approximate reasoning, Inf. and Sci., 8, 199-249, 1975.

Zêzere, J. L., Reis, E., Garcia, R., Oliveira, S., Rodrigues, M. L., Vieira, G., and Ferreira, A. B.: Integration of spatial and temporal data for the definition of different landslide hazard scenarios in the area of north of Lisbon (Portugal), Nat. Hazards Earth Syst. Sci., 4, 133-146, 2004,

SRef-ID: 1684-9981/nhess/2004-4-133. 